Background: Oesophageal squamous cell carcinoma is one of the most common malignancies in China. The association of trace elements and high cancer risk has been found in many studies. The present study was performed to in vestigate the relationship between the concentration of magnesium, copper and chrome and the incidence and prognosis of oesophageal squamous cell carcinoma.

Material and methods: The study was conducted on 36 patients with oesophageal squamous cell carcinoma and all patients underwent oesophagectomy. The cancerous tissue samples and the normal tissue samples came from the patients. The concentration of magnesium, copper and chrome was measured by flame atomic absorption spectroscopy and comparison was made using Student's $t$-test. Results: The content of magnesium in cancerous tissues was significantly lower than that in the normal tissues. In contrast, copper level in cancerous tissues was significantly higher than that in the normal tissues. Copper level in patients with lymph node metastasis was significantly higher than in patients without lymph node metastasis. There was a significant increase in mean copper in cancerous tissues with a worse histological grade. Our study showed that a lower magnesium level and a higher copper level may play an important role in oesophageal squamous cell carcinoma induction. And the chrome level may not be associated with the induction of oesophageal squamous cell carcinoma.

Key words: chrome, copper, magnesium, oesophageal squamous cell carcinoma.

\section{Clinical study on magnesium, copper and chrome levels in patients with oesophageal squamous cell carcinoma}

\author{
Zhi-Gang Sun ${ }^{1}$, Guang-Min Song ${ }^{2}$, Min Zhang ${ }^{3}$, Zhou Wang ${ }^{4}$, Zhi-Hong Ni ${ }^{5}$
}

1Department of Thoracic Surgery, Jinan Center Hospital Affiliated to Shandong University, Provincial Hospital Affiliated to Shandong University, Jinan, China 2Department of Cardiovascular Surgery, Qi Lu Hospital Affiliated to Shandong University, Jinan, China

${ }^{3}$ Department of Dermatology, Jinan Center Hospital Affiliated to Shandong University, Jinan, China

4Department of Thoracic Surgery, Provincial Hospital Affiliated to Shandong University, Jinan, China

${ }^{5}$ Department of Stomatology, No. 456 Hospital of Jinan Army Region, Jinan, China

\section{Introduction}

Oesophageal squamous cell carcinoma (ESCC) is one of the most common malignancies treated by thoracic surgeons in China. However, the precise mechanisms that underlie the development and progression of ESCC are far from clear. The association of trace elements and high cancer risk has been found in many studies [1-3]. These trace metals are included in magnesium, copper and chrome, etc. Magnesium is required in multiple functions and in all cellular processes. Over 300 enzymes that influence the metabolism of carbohydrate, amino acids, nucleic acids and protein require magnesium. It is very important for DNA stability [4]. Copper is a cofactor for enzymes, including copper superoxide dismutase. Copper catalyses the formation of reactive oxygen species, and oxidative processes are among the mechanisms involved in both occurrence and recurrence of some cancers. Oxidative stress causes severe damage to biological macromolecules and dysregulation of normal metabolism and physiology. Oxidative damage has been linked to chronic copper and overload $[4,5]$. Chrome, like many transition metal elements, is essential to life at low concentrations, yet toxic to many systems at higher concentrations. In addition to the overt symptoms of acute chromium toxicity, delayed manifestations of chrome exposure become apparent by subsequent increases in the incidence of various human cancers. Chrome, in its myriad chemical forms and oxidation states, has been well studied in terms of its general chemistry and its interactions with biological molecules. Although recent studies have suggested that reduction of chrome $(\mathrm{VI})$ to its lower oxidation states and related free-radical reactions play an important role in carcinogenesis, the precise mechanisms by which chrome is both an essential metal and a carcinogen are not yet fully clear [6].

To our knowledge, the majority of studies between the concentration of magnesium, copper and chrome and oesophageal cancer have been measured in serum, scalp hair or dietary level in China. In this study, we use the patients' cancerous tissues and normal oesophageal tissues, and the aim of the study is to investigate the relationship between the concentration of magnesium, copper and chrome and the incidence and prognosis of ESCC.

\section{Material and methods}

Patients and sampling

This study was conducted on 36 patients registered at the Department of Thoracic Surgery, Jinan Center Hospital Affiliated to Shandong University, Shan- 
dong Province, China. The study was approved by the medical ethics committee for human studies of Shandong University of Medical Sciences. All patients underwent oesophagectomy with systematic lymph node dissection. The tumour could be confirmed as oesophagus squamous cell cancer and the oesophagus tangent line could not be found to have tumour tissue by pathology. Histological examination also confirmed that there was no residual tumour in any of the patients. None of these patients had received preoperative therapy.

The patients consisted of 25 men and 11 women ranging in ages from 45 to 78 years (mean: 58 years). On the basis of the TNM classification of the International Union against Cancer (UICC) in 1997, 4 patients had pT1 disease, 12 patients had pT2 disease, 15 patients had pT3 disease, and 5 patients had pT4 disease. Among these patients, 8 patients' histological grade belonged to grade I, 17 cases belonged to grade II, and the others belonged to grade III. 15 patients had lymph node metastasis, 21 patients did not. The cancerous tissue samples came from oesophagus squamous cell cancers, while the normal tissue samples came from the patients' normal oesophagus $(6 \mathrm{~cm}$ away from the oesophagus squamous cell cancers).

\section{Biochemical measurements}

The sample was put into a conical flask after weighing, and $10 \mathrm{ml}$ of azotic acid was put into the conical flask. The next day $0.6 \mathrm{ml}$ of perchloric acid was added. Then the sample was heated until it dissolved. The stock suspension was

Table 1. Mean \pm SD of magnesium, copper and chrome in cancerous tissues and control group ( $\mu \mathrm{g} / \mathrm{g}$ humid weight)

\begin{tabular}{lccc|} 
Case & $\begin{array}{c}\text { Cancerous tissues } \\
n=36\end{array}$ & $\begin{array}{c}\text { Normal tissues } \\
n=36\end{array}$ & $P$ \\
\hline Magnesium & $242.14 \pm 17.76$ & $260.67 \pm 22.57$ & $<0.01$ \\
Copper & $1.34 \pm 0.11$ & $1.023 \pm 0.084$ & $<0.01$ \\
\hline Chrome & $6.087 \pm 0.601$ & $5.56 \pm 0.678$ & $>0.05$
\end{tabular}

Table 2. Mean \pm SD of magnesium, copper and chrome in cancerous tissues with lymph node metastasis ( $\mu \mathrm{g} / \mathrm{g}$ humid weight)

\begin{tabular}{lccc} 
Case & $\begin{array}{c}\text { Lymph node } \\
\text { metastasis } \\
n=15\end{array}$ & $\begin{array}{c}\text { No lymph node } \\
\text { metastasis } \\
n=21\end{array}$ & $P$ \\
\hline Magnesium & $238.47 \pm 32.70$ & $244.57 \pm 21.91$ & $>0.05$ \\
\hline Copper & $1.568 \pm 0.16$ & $1.175 \pm 0.122$ & $<0.01$ \\
\hline Chrome & $6.29 \pm 0.97$ & $5.94 \pm 0.83$ & $>0.05$
\end{tabular}

metered to a volume of $5 \mathrm{ml}$. A Hitachi atomic absorption/flame spectrophotometer was used to determine the trace element. The concentrations of magnesium, copper and chrome were measured by flame atomic absorption spectroscopy.

\section{Statistical analysis}

Values were expressed as mean \pm standard deviation (SD). Data was analysed using SPSS 13.0 software. Comparisons were made using Student's $t$-test. $P$-values less than 0.05 were considered to be significant.

\section{Results}

The levels of magnesium, copper and chrome belonging to cancerous tissues and control groups are summarized in Table 1. The content of magnesium in cancerous tissues was significantly lower than that in the normal tissues $(p<0.01)$. In contrast, copper level in cancerous tissues was significantly higher than that in the normal tissues $(p<0.01)$. There was no statistically significant difference in chrome level between the cancerous tissue group and the normal tissue group $(p>0.05)$.

Table 2 shows that copper level in patients with lymph node metastasis was significantly higher than in patients without lymph node metastasis $(p<0.01)$. And no statistically significant correlations with magnesium level and chrome level were demonstrated for lymph node metastasis $(p>0.05)$.

Comparing histological grade II with I, and III with I, there was a significant increase in mean copper in cancerous tissues with worse histological grade $(p<0.01, p<0.01)$, and there was no statistically significant difference in copper level between histological grades II and I. There was no statistically significant difference in magnesium level and chrome level between histological grades II and I, III and II, or III and I. These data are summarized in Table 3.

Table 4 shows that no statistically significant correlations with copper level, magnesium level and chrome level were demonstrated for T status $(p>0.05)$. And table 5 shows that no statistically significant correlations with copper level, magnesium level and chrome level were demonstrated for gen$\operatorname{der}(p>0.05)$.

\section{Discussion}

This study examined the relationship between magnesium, copper and chrome level and ESCC. The performed analysis of magnesium, copper and chrome level demonstrated a significant difference between oesophageal cancer tissues and oesophageal normal tissues.

Table 3. Mean \pm SD of magnesium, copper and chrome in cancerous tissues with different histological grade ( $\mu \mathrm{g} / \mathrm{g}$ humid weight)

\begin{tabular}{|c|c|c|c|c|c|c|}
\hline Case & $\begin{array}{c}1 \\
n=8\end{array}$ & $\begin{array}{c}\| \\
n=17\end{array}$ & $\begin{array}{c}\text { III } \\
n=11\end{array}$ & $P 1$ & P2 & P3 \\
\hline Magnesium & $262.5 \pm 43.32$ & $244.12 \pm 28.28$ & $223.91 \pm 30.97$ & $>0.05$ & $>0.05$ & $>0.05$ \\
\hline Copper & $1.052 \pm 0.202$ & $1.22 \pm 0.12$ & $1.70 \pm 0.13$ & $>0.05$ & $<0.01$ & $<0.01$ \\
\hline Chrome & $5.98 \pm 1.30$ & $6.22 \pm 1.10$ & $5.96 \pm 0.94$ & $>0.05$ & $>0.05$ & $>0.05$ \\
\hline
\end{tabular}

P1: II was compared with I; P2: II was compared with 1; P3: II was compared with II 
The relationship between magnesium and cancer is complex and contradictory. Both magnesium load and deficit can produce carcinogenic and anticarcinogenic effects. There is evidence, both epidemiological and clinical, supporting the hypothesis that magnesium deficiency could cause some cancers [7]. However, disorders in magnesium distribution in carcinogenesis are far more complex than what can be found in simple magnesium deficiency. The role of magnesium in carcinogenesis is not clear. The relationship with tumour formation is more complex and magnesium appears to be protective at early stages, but promotes the growth of existing tumours at later stages. Since magnesium is required in multiple functions and in all cellular processes, and is important for DNA stability as well as genomic stability, any decrease of magnesium below physiological levels could trigger magnesium deficiency related diseases, such as cardiovascular disease, accelerated aging and cell cycle control apoptosis and carcinogenesis [8]. Thus, magnesium concentrations play a vital role in cell cycle regulation, enzyme activity, in promoting growth, muscle efficiency, etc. If magnesium is not at physiological levels, then mutations may accumulate, since it is known that magnesium keeps mutations low by helping DNA repair processes through the efficiency of repair enzymes.

In our study, the analysis of magnesium level demonstrates that in the oesophageal cancer group, the magnesium level in cancerous tissues is significantly and remarkably lower than the normal group. Our finding is in agreement with most of the earlier studies suggesting that in the cancer group magnesium level is lower. This demonstrates that the measurement of magnesium level may be associated with the aggression of ESCC.

The analysis of copper level demonstrates that in the oesophageal cancer group, the copper level is significantly and remarkably higher than the normal group. Copper level in patients with lymph node metastasis was significantly higher than in the control group. Also, the worse the histological grade in oesophagus squamous cancer, the higher is the copper level. Our finding is in agreement with most of the earlier studies suggesting that in the oesophageal cancer groups serum copper is higher [9-11]. Also, copper chelation by chelating agents has antiproliferative effects in many studies [12]. Brewer et al. tested a drug known as tetrathiomolybdate, which binds up dietary copper in patients with different kinds of cancer. In the patients, tumours did not grow and no new tumours formed [13]. It is known that copper participates in the reductive activation of hydrogen peroxide $\left(\mathrm{H}_{2} \mathrm{O}_{2}\right)$, causing damage to cellular DNA, proteins and lipids. The interaction of $\mathrm{H}_{2} \mathrm{O}_{2}$ with copper generates more reactive oxygen species, such as hydroxyl radicals. These reactive oxygen species have been considered as being responsible for the process of carcinogenesis, and oxidative processes are considered to be among the mechanisms involved in bladder cancer [14]. Therefore, our findings suggest that ESCC progression may be due to the catalysis of oxidative stress by increased copper level.

Since the early 1980s both the International Agency for Research on Cancer (IARC, 2000) and the National Toxicology Program of the United States (NTP, 2000) have cate-
Table 4. Mean \pm SD of magnesium, copper and chrome in cancerous tissues with $\mathrm{T}$ status ( $\mu \mathrm{g} / \mathrm{g}$ humid weight)

\begin{tabular}{lccc} 
Case & $\mathrm{T} 1+2$ & $\mathrm{~T} 3+4$ & $P$ \\
& $n=16$ & $n=20$ & \\
\hline Magnesium & $233.6 \pm 16.72$ & $248.8 \pm 30.01$ & $>0.05$ \\
Copper & $1.29 \pm 0.18$ & $1.38 \pm 0.16$ & $>0.05$ \\
\hline Chrome & $6.49 \pm 1.065$ & $5.76 \pm 0.722$ & $>0.05$
\end{tabular}

$T: T$ status

Table 5. Mean \pm SD of magnesium, copper and chrome in cancerous tissues with gender ( $\mu \mathrm{g} / \mathrm{g}$ humid weight)

\begin{tabular}{lccc} 
Case & Male & Female & $P$ \\
& $n=25$ & $n=11$ & \\
\hline Magnesium & $254.84 \pm 24.61$ & $364.27 \pm 35.63$ & $>0.05$ \\
Copper & $1.37 \pm 0.14$ & $1.27 \pm 0.22$ & $>0.05$ \\
\hline Chrome & $6.098 \pm 0.69$ & $6.335 \pm 1.51$ & $>0.05$
\end{tabular}

gorized chrome as a human carcinogen [15]. This is based on epidemiologic evidence that chrome in valence state six causes cancers of the lung, the nose, and the nasal sinuses. It is generally accepted that only chrome in valence state six is carcinogenic. There has been concern that chrome in valence state six may also cause stomach cancer because a portion of chrome dust inhaled in occupational settings could become trapped in mucus and swallowed. It is also possible that chrome in valence state six in drinking water would reach the stomach. Cole and Rodu [6] used 49 epidemiological studies based on 84 papers published since 1950 to develop an array of meta-analyses relating exposure to chromesix compounds with 10 causes of death. This series of metaanalyses indicates that chrome-six is a weak cause of lung cancer.

In our study, the chrome level in cancerous tissues was higher than that in the normal tissues. However, there was no statistically significant difference in chrome level between the cancerous tissues group and the control group. This demonstrates that the chrome level may not be associated with the aggression and prognosis of primary oesophageal squamous cell cancer.

In conclusion, the presence of an association between ESCC and magnesium, copper and chrome was observed in the present study. We also suggest that a lower magnesium level and a higher copper level may play an important role in ESCC induction. The measurement of copper level may be associated with the incidence, aggression and prognosis of ESCC. The chrome level may not be associated with the aggression and prognosis of primary oesophageal squamous cell cancer. However, defining such a cause-and-effect relationship needs several prospective studies to be done, which seems necessary with regard to the high prevalence of this cancer in China.

\section{Acknowledgments}

The authors have no financial affiliation or involvement with any commercial organization with direct financial in- 
terest in the subject or materials discussed in this manuscript. The authors would like to thank Shan Dong University for its cooperation.

\section{References}

1. Cobanoglu U, Demir H, Sayir F, Duran M, Mergan D. Some mineral, trace element and heavy metal concentrations in lung cancer. Asian Pac J Cancer Prev 2010; 11: 1383-8.

2. Kim SY, Kim JW, Ko YS, Koo JE, Chung HY, Lee-Kim YC. Changes in lipid peroxidation and antioxidant trace elements in serum of women with cervical intraepithelial neoplasia and invasive cancer. Nutr Cancer 2003; 47: 126-30.

3. Milde D, Novák O, Stužka V, Vysloužil K, Macháček J. Serum levels of selenium, manganese, copper, and iron in colorectal cancer patients. Biol Trace Elem Res 2001; 79: 107-14.

4. Cobanoglu U, Demir H, Sayir F, Duran M, Mergan D. Some miner$\mathrm{al}$, trace element and heavy metal concentrations in lung cancer. Asian Pac J Cancer Prev 2010; 11: 1383-8.

5. Leone N, Courbon D, Ducimetiere P, Zureik M. Zinc, copper, and magnesium and risks for all-cause, cancer, and cardiovascular mortality. Epidemiology 2006; 17: 308-14.

6. Cole P, Rodu B. Epidemiologic studies of chrome and cancer mortality: a series of meta-analyses. Regul Toxicol Pharmacol 2005; 43: 225-31.

7. Anastassopoulou J, Theophanides T. Magnesium-DNA interactions and the possible relation of magnesium to carcinogenesis. Irradiation and free radicals. Crit Rev Oncol Hematol 2002; 42: 79-91.

8. Hartwig A. Role of magnesium in genomic stability. Mutat Res 2001; 475: 113-21.

9. Goyal MM, Kalwar AK, Vyas RK, Bhati A. A study of serum zinc, selenium and copper levels in carcinoma of esophagus patients. Indian J Clin Biochem 2006; 21: 208-10.

10. Dar NA, Mir MM, Salam I, Malik MA, Gulzar GM, Yatoo GN, Ahmad A, Shah A. Association between copper excess, zinc deficiency, and TP53 mutations in esophageal squamous cell carcinoma from Kashmir Valley, India - a high risk area. Nutr Cancer 2008; 60: 585-91.

11. Hronek M, Zadak Z, Solichova D, Jandik P, Melichar B. The association between specific nutritional antioxidants and manifestation of colorectal cancer. Nutrition 2000; 16: 189-91.

12. Mross K. Anti-angiogenesis therapy: concepts and importance of dosing schedules in clinical trials. Drug Resist Updat 2000; 3: 223-35.

13. Valko M, Rhodes CJ, Moncol J, Izakovic M, Mazur M. Free radicals, metals and antioxidants in oxidative stress-induced cancer. Chem Biol Interact 160: 1-40.

14. Yilmaz IA, Akcay T, Cakatay U, Telci A, Ataus S, Yalcin V. Relation between bladder cancer and protein oxidation. Int Urol Nephrol 2006; 35: 345-50.

\section{Address for correspondence}

\section{Guang-Min Song MD}

Department of Cardiovascular Surgery

Qi Lu Hospital Affiliated to Shandong University

Jinan, China

e-mail: songguangminszg@126.com 